\title{
Household Coping Strategies of Water Scarcity: The Case of Madina, A Suburb of the La- Nkwantanang District in the Greater Accra Region
}

\author{
Richard Senna \\ School of Social Sciences, Evangelical Presbyterian University College \\ PO HP 678, Ho, Volta Region, Ghana
}

\begin{abstract}
The study examines the precipitating factors for water shortage and water shortage effects on Madina residents, a peri-urban community of Accra, and the forms of coping mechanisms adopted due to water scarcity. The study utilised both primary and secondary data; results revealed that the following effects of water scarcity on residents: lateness to school, inadequate sleep, a more significant percentage of family income and time used on water, increased poverty, low productivity and poor sanitation among others. The forms of coping mechanisms include harvesting rainwater, using bagged or sachet water, multiple uses of water, depending on public toilets. The topography of the Madina, few boreholes or wells, lack of pipe-born water, lack of maintenance of pipelines, increase in population, and lack of projections for the future constitute reasons for water shortage in the study area. The effects of water shortage gave rise to coping strategies and social conflict, which also have socioeconomic implications on residents. The study concludes that GWCL has not been able to satisfy the everincreasing water demands of urban dwellers, including peri-urban communities such as Madina, that the agelong water crisis in Madina affects all aspects of the social and economic lives of its residents. Recommendations include the incorporation of roof-water harvesting techniques into modern buildings' design. Also, the hygienic use of greywater must be vigorously promoted. The Government of Ghana must also continue to engage in open consultation with stakeholders regarding alternative approaches to expanding access to clean and affordable water, mainly to the urban dwellers where the problem is most severe.
\end{abstract}

Keywords: water scarcity, coping strategies, households.

DOI: $10.7176 / \mathrm{JRDM} / 76-05$

Publication date:June $30^{\text {th }} 2021$

\subsection{Introduction}

The quest for clean and safe water has become enormous more than ever. Indeed, no part of the world is immune to the problem of water scarcity. In many parts of the world, easily accessible water sources have already been tapped, supplies are approaching their physical limits, and new supplies for growing populations and rising consumption are available only at increasing cost. As a result, the depletion of freshwater supply for domestic, industrial and agricultural purposes is likely to become the single most important environmental issue facing many societies globally, especially urban dwellers. Even countries not yet facing water crises are likely to experience significant increases in the cost of providing water to meet ever-growing demands. Indeed, improving the planning, management and conservation of water is now more critical than ever before to achieve economic development.

Water is one of life's necessities with no substitute; it is the biosphere's lifeblood (Falkenmark and Rockstrom, 2004). Water supports socioeconomic activities such as agriculture, mining, food production, and maintaining healthy ecosystems. Water scarcity is an imbalance between demand and availability and exists when the demand exceeds the supply (Molle and Molinga, 2003). This scarcity may result from a range of phenomena, including natural causes, human activities, or may result from the interaction of both (Vlachos and James, 1983).

It is instructive to note that public water suppliers in developing countries are routinely criticised for failing to provide adequate water services to urban dwellers, especially the urban poor. Often, these institutions are large and inefficient and unable to deliver quality services to the public. Despite the massive physical development characteristics of most cities, they have not met city dwellers' needs (Kenneth, 1997). Zane (1973) also noted that various factors account for governments' deplorable performance in meeting city dwellers' water needs. One of such factors is rapid population growth. He noted that many urban areas simply find it impossible to keep up with the expanding needs for light, transportation, sewerage, and water.

According to the Stockholm Environmental Institute (2002), a third of the world's population already live in areas that suffer moderate to severe water shortage. The water demand has risen at more than twice the rate of the population increase. Water supply, on the other hand, is fixed. Deeper wells and new reservoirs may bring temporary relief, but the amount of rain that falls on the earth and the amount of water stored under the ground essentially remain the same. Therefore, meteorologists calculated that within 25 years from now, the quantity of 
water available to each person on earth might be cut in half (The Green Dove Magazine, 2005). Indeed, the majority of the world's population struggle to access clean water daily. However, it is necessary to remember that only 20 per cent of humankind enjoys such luxuries (Takashi, 1999). According to Oppong (2004), many women in Africa spend as much as six hours a day fetching water and frequently, it is polluted. These women comprehend much more the harsh reality. Clean, safe water is scarce, and it is getting scarcer.

Water scarcity is a stark reality in most cities in the developing world, including Ghana. An integrated urban water resource management plan will empower Madina communities to decide on access to safe water and hygienic living conditions.

In a joint WHO/UNICEF publication (2005), It was reported that It is not hard to see why providing access to safe drinking water and basic sanitation for the world's most deprived populations is moving up the political agenda. With 2.6 billion people recorded as lacking any improved sanitation facilities in 2002 and 1.1 billion of them without access to an improved drinking water source, the resulting squalor, poverty and disease hold back so many development efforts. Focusing efforts on achievement of the MDG drinking water and sanitation target will speed progress towards all eight goals.

The 2005 Water Aid report (Ghana Water Sector Assessment, 2005) revealed that Ghana's water supply coverage was $75 \%$ (52 percent rural/small towns and 88 percent for urban areas but $37 \%$ household connections). The report lamented that in the urban area, Ghana faces serious constraints to meeting the challenge of providing adequate water for all residents. These include the dire and worsening financial condition of the urban utility. It added that the Ghana Water Company Limited (GWCL) has suffered insufficient sector investment over the last ten years. This was furthered exacerbated by weak management and implementation capacity caused by human resource issues. The report intimated that approximately 10.7 million people (53\%) have access to improved water supplies in Ghana. Sixty one percent of the 8.4 million residents in the country's urban areas have improved water supply services provided by GWCL's networks. Hence, 3.3 million urban residents in Ghana depend on alternative water sources. The relevant questions are: what is peculiar about the Madina water problem? What are the reasons behind the community's prolong history of water scarcity? Is it a question of engineering problem?

In the light of these and other such questions, this study seeks to find out the peculiarity of the Madina water problem, coping mechanism adopted by residents in the face of persistent inadequate water for domestic use. Therefore, a study of this nature has become necessary in the Madina community, mainly due to its long history of water scarcity and its social and economic implications. The study's objective is to find out how residents of the Madina community located in Accra's urban area cope with water scarcity and document such coping strategies among residents.

\subsection{Literature Review}

\subsection{The Global Water Situation}

One of the phenomenal developments that accompanied the industrial revolution in the $18^{\text {th }}$ century was cities' growth. The industrial revolution saw more and more factories and economic production points and activities concentrated in the world's newly emerging urban areas. This development led to a significant movement of labour to these new production centres, leading to rapid growth of urban societies worldwide. It is important to note that this massive concentration of people in urban areas brought in its wake new social and economic problems that confronted urban dwellers, including water scarcity (Roland et al 1994).

Water is a fundamental part of human life; it is easy to forget how completely we depend on it. Human survival depends on water; experts have ranked it second only to oxygen as essential to life (The Mirror, January 7, 2006). The article noted that at the dawn of the new millennium, several factors led the world slowly towards a severe water crisis: the increasing demand for water for domestic and agricultural use, change in consumption patterns, desertification, pollution and inadequate infrastructure were factors responsible. It is no longer in dispute that thirty-one countries, mainly in the Middle East and Africa, have severe water shortages (The Green Dove Magazine, 2005). No wonder it is commonly held now that 'the war of the $21^{\text {st }}$ century will be fought over water'. Again, it is projected that by the year 2025, 17 countries will be added to this list, including Ethiopia, India and Nigeria (African Agenda, 2004).

In a review of the current global water crisis in 2004, the African Agenda, a South-Africa based magazine made some valid observations about the current trends, especially in the ever fast-growing urban communities. It noted that about 1.4 billion people (one out of five) lack access to clean drinking water and about 80 countries (some 40 per cent of the world's population) had experienced water shortages by the 1990s. The U.N. has estimated that even though water supply is expected to increase globally by 40 per cent by 2020, two-thirds of the world's population will experience shortages of clean water, with Africa expected to be the hardest-hit continent. This is because whilst the average African family uses five gallons of water a day, its American counterpart uses about 100 gallons a day. Besides, it was intimated that about a quarter of Africans in the urban centres spend 10 - 20 per cent of their income on water. 
According to Winpenny (1994), water is becoming one of the largest and certainly the universal problems facing humankind as the earth moves into the twenty-first century. It is noted that supplying enough water of the required quality to growing populations and the safe disposal of wastewater are straining many authorities to the limit. It is argued that the leading cause for the current water situation globally is the failure to treat water as a scarce commodity. One major cause of water scarcity globally is water bodies' pollution, which serves as the primary source of drinking water to many communities. According to Kenneth et al. (1997), contaminated water is a significant problem even in the United States. Over the years, virtually every major body of water in the nation has been polluted. In this direction, if nothing is done to reverse present trends, the number of people without access to drinking water in the years 2025 will rise above 4 billion, half the world' population (Riccardo, 2001). Roland et al., 1994, noted that though significant progress has been made during the "International Water Supply and Sanitation Decade (1981-1990), about 25 per cent of the urban residents are still not served with safe drinking water. Of all the basic needs, water is undeniably the most essential to survival and individual health and family welfare. Nevertheless, it is one commodity that people are least able to provide for themselves, particularly in our part of the world.

The PRONET magazine in 2004 revealed in an article that Africa has the lowest water supply coverage globally; more than 1 in 3 Africans do not have access to improved water supply facilities. It further pointed out that the coverage level in the year 2000 for water was 62 per cent. The sad reality is that the absolute number of people without water is increasing, and unless drastic actions are taken, the absolute number will double between now and the year 2020 from 200 million to 400 million. It added that majority of these people will be those living in rural, informal and peri-urban communities.

\subsection{The Causes of the Global Water Scarcity}

Looking at the current gloomy water situation globally, Winpenny (1994) pointed out that several factors account for many societies' inability to meet their growing water demands. In the first place, in many situations, supply systems and consumption habits have failed to adapt to the increasing pressure of demand on the water resources and the environmental strains that it causes. In wetter parts of the world, water availability has been taken for granted, its provision has been a routine operation, and engineering solutions have tended to predominate. In drier regions, water has always been a central preoccupation, and many different kinds of social arrangements have risen to deal with the allocation and use of this scarce resource. In these regions, the age-old problem is everywhere becoming more severe in the face of population growth and economic development.

Additionally, in most cases, water has been underpriced as an economic resource. Users do not, in general, treat water as an economic (that is, scarce) commodity, and the market is insufficiently used as a means of solving the problem of scarcity. In the same situation, water is available to users at little or no cost. For instance, with communities relying on natural supplies such as small-scale roof catchments; once the relatively small installation cost has been paid for, this water becomes free for all, for all practical purposes (Winpenny, 1994).

\subsection{The State of Urban Water Supply in Ghana}

In a publication on the water situation urban communities in Ghana, Aryeetey \& Kanbur in 2006 noted that since independence, Ghana's population has quadrupled when 35 urban pipe-borne systems were constructed and currently, 35 per cent of the population is urban. It revealed that about 58 per cent of urban water supply goes to domestic consumption, 24 per cent to commercial/industrial customers and 18 per cent to government and public institutions. The publication opined that effective urban water supply coverage keeps decreasing from the 2002 figure of 59 per cent, just as the year's investment keeps dwindling, noting that forty-one per cent of citizens have either no access to or get water through savvy tanker operators and vendors who charge very unusual rates. This is not due to water scarcity, as 50 per cent of water goes unaccounted for aside from widespread leakages.

Of particular importance to urban dwellers is the quality of water they drink (ref). The World Health Organization (WHO, 2000) publication says that 75 per cent of all diseases in developing countries arose from polluted drinking water. The report claims every dollar spent on improving water delivery and sanitation would bring US\$34 of benefit (Cudjoe, 2004).

\subsection{Coping Strategies}

The issue of water inadequacy has become a global social problem, particularly at the household level. As a result, households employ various strategies to mitigate or cope with the risks that unreliable water supplies pose. This section reviews some of these coping strategies often adopted by individual households in managing the situation.

According to Dutta \& Tiwari (2005), households respond to unreliable water supplies through various coping strategies. Parallel to this is the costs that are associated with the various coping strategies. Direct coping costs refer to expenditures arising from installing fixtures to augment the water supply such as drilled wells, electric pumps and storage tanks, purchase of water and treatment of water. 
In their conceptual framework, Kudat et al. (1993) and Humplick et al. (1993) argued that as a commodity, water has three main attributes: quantity, quality and pressure. Where the water supply does not meet the optimum levels of these three attributes, the supply is said to be unreliable, and households will adopt strategies to mitigate risks from this unreliability. These activities can be broadly categorised as extending on the concept of "exit, voice and loyalty". They further stated that faced with chronic unreliability, households may 'exit' the unreliable water system by adopting strategies such as drilling wells, installing large capacity storage tanks or even relocating to areas where the water supply is more reliable. The 'voice' strategy includes complaints and protests to water utilities or local authorities. Households could also be loyal and engage in accommodative strategies such as rescheduling activities to when water is actually available, collecting from alternative sources and consuming less water

The authors also suggest that factors associated with the choice of coping strategies can be grouped into three levels: (i) household-level, e.g. socioeconomic status, gender, age structure; (ii) settlement level, e.g. water service level, formal/informal settlement and (iii) national level, e.g. urbanisation, privatisation of water supply sector, regulatory and policy framework (Humplick et al., 1993, Kudat et al., 1997). Subsequent studies have drawn upon Kudat et al., focusing mainly on measuring the costs of coping strategies (Choe et al., 1996, Zerah, 1998, Zérah, 2000b) as indirect estimates of willingness to pay for more reliable services.

The lack of adequate water supply in some parts of Ghana has resulted in residents' various coping strategies. According to the Ghana Statistical Service (2000), most residents in Accra, the capital city of Ghana, rely on GWCL water sources directly or indirectly through secondary and tertiary service providers. However, only 9.8 per cent of inhabitants in Accra have house-connection with indoor plumbing. The other inhabitants rely on house connections with inside standpipe or yard connection (38.7 per cent), water vendors (15.7 per cent), tankered water ( 0.3 per cent), neighbours ( 22.3 per cent), private outside standpipe (13.1 per cent) and public standpipe ( 0.2 per cent).

According to G. Tanoh and K. Cusack (2003), the Government of Ghana estimates that about 66 per cent of urban residents have access to potable water. However, 78 per cent of the urban poor do not have regular access to potable water because they lack connections. This majority of urban residents buy their daily supplies from water merchants at an average cost of USD 0.34 (August 2002 prices) or 54 per cent of the minimum daily wage.

In the situation of scarcity, there is a need for adaptation. In order words, residents have to develop coping mechanisms to deal with the situation. According to the Integrated Regional Information Networks of the United Nations Office for the Coordination of Humanitarian Affairs (2004), residents in Teshie, a suburb of Accra, buy water in buckets from private vendors "because the taps have been off for more than five years." They pay between 8 and 10 U.S. cents for 4 gallons of water transported by a tanker truck. The report indicated a "big slice" of the family income where the average minimum wage is only $\$ 1$ per day. It also revealed that in Accra, a city of more than 4 million people, "only the smartest residential areas, where diplomats, wealthy businessmen and government officials tend to live could count on a regular water supply." Those who can afford it have taken to storing water when taps run in a few hours at a time or three times a week in their area. The saddening and dangerous revelation is that "some people now ration water and use one bucket for bathing three kids as a coping mechanism.

\subsection{Methodology}

\subsection{Description of Study Area}

The Ga East District Assembly used to be part of the now-defunct Ga District Assembly divided into two. It was established in 2004 by Legislative Instrument 1589. The Ga East District Assembly (GEDA) is one of the six Districts in the Greater Accra Region and covers $166 \mathrm{sq} \mathrm{km}$. It is bordered on the West by Ga West District, on the East by the Tema Municipality, the South by Accra Metropolitan Assembly (AMA) and the North by the Akwapim South District Assembly.

According to the Population and Housing Census (2000), the District's population is estimated to be 450, 200, with about 174 settlements with Abokobi as the District capital. The population is mainly along the District's urban and peri-urban areas, particularly along the border with the AMA, including Madina, Taifa, Dome and Haatso. As the study area, Madina has an estimated population of about 67,000 with an annual growth rate of about 8.3 per cent. The urban and the peri-urban population constitute about 73 per cent, with the remaining 27 per cent residing in the rural portion towards the Akwapim Hills. The District falls within the Savannah agro-ecological zone.

\subsection{Study Sample and Selection Techniques}

The study focuses on water scarcity and coping strategies within Madina. As a result, the study targets all residents and private water vendors in the study area; in this case, all households and private water suppliers formed the target population. This is because both the various homes and water suppliers directly experience the water problem in the study area. Having identified the target population, households, service providers (GWCL) 
and water vendors constituted the study population from which information was collected for the study.

The study's sampling units consisted of households, service providers (GWCL) and private water vendors. This sampling unit then served as units for analysing information from the households under study. The list of all households in the study area, and private water suppliers served as the sampling frame from which the sample size was chosen and where information was collected for the study. In this regard, a sample size of 150 respondents was proportionally drawn from both low and high-income households in the study area.

\subsection{Data Collection}

The student employed both primary and secondary sources of information. Multistage stratified random sampling was conducted to select 150 households. Information was collected on socioeconomic characteristics, water consumption and coping measures. There was an initial familiarisation tour of the area to have a firsthand picture of the problem of water scarcity in the area. This was also used to establish rapport with the study area residents and have informal interactions with some residents and private water vendors. The collection of data from primary sources included interviews, self-administered questionnaires, and personal observations.

\subsection{Data Analysis}

The data were analysed using the Statistical Package for the Social Sciences (SPSS). The chi-square test was used to examine association income levels and coping strategies.

\subsection{Ethical Considerations}

The study considered some ethical issues in gathering information from respondents. This was to ensure that respondents did not suffer any harm in the process. In the first place, since most of the respondents were either petty traders or formal workers and therefore very busy, they were allowed to answer the questionnaire at their own convenience. Also, those who were unwilling to talk to the researcher, probably due to time constraints, were not forced to do so. This was to ensure that participation was voluntary and not forced. Also, the researcher sought permission from each respondent before him or her. This was to ensure that their privacy was not unduly invaded.

\subsection{Results and Discussions}

4.1 Socioeconomic description of households

Table 1 contains some selected socioeconomic demographics of respondents.

Table 1: Socioeconomic description of households

\begin{tabular}{|c|c|c|c|}
\hline \multirow{7}{*}{$\begin{array}{c}\text { Level of } \\
\text { Education }\end{array}$} & Educational Level & Frequency & Per cent \\
\hline & No formal education & 8 & 5.3 \\
\hline & Primary & 14 & 9.3 \\
\hline & Middle school/JSS & 36 & 24.0 \\
\hline & SHS / O’Level / A'Level & 45 & 30.0 \\
\hline & Polytechnic & 7 & 4.7 \\
\hline & University & 40 & 26.7 \\
\hline \multirow{5}{*}{$\begin{array}{c}\text { Employment } \\
\text { status }\end{array}$} & Category & Frequency & Per cent \\
\hline & Self-employed & 56 & 37.3 \\
\hline & Employed (Informal private sector) & 30 & 20.0 \\
\hline & Employed (Formal public sector) & 52 & 34.7 \\
\hline & Unemployed & 12 & 8.0 \\
\hline
\end{tabular}

Based on educational attainment, residents were classified into different educational categories. A higher number of respondents $(45,30 \%)$ had attained secondary education, with 40 others $(26.7 \%)$ reaching the University level. Seven respondents $(4.7 \%)$ were polytechnic graduates. The rest included 14 respondents $(9.3 \%)$ who had only primary education, 36 (24\%) who had middle/JSS education and eight respondents $(5.3 \%)$ who had no formal education.

One significant determinant of one's access, or otherwise to social services or basic needs, is one's means of earning income. This is because a persons' level of income determines his daily access to certain basic needs such as water and his ability to afford such services. The majority (37.3 per cent) of respondents interviewed for this study were self-employed and engaged mainly in petty trading, artisanship, and driving (others also employ some drivers). Also, 30 respondent constituting 20.0 per cent worked in the private sector whilst only 34.7 per cent worked in the public sector. It is important to note that some residents were also unemployed. Specifically, 12 respondent ( 8.0 per cent) reported being unemployed. 


\subsection{Causes of the Water Shortage in Madina}

In a very effective service delivery system, it is essential to consider the perceptions and opinions of consumers about the services. If customers' (or consumers') perceptions are taken into account, it goes a long way to improve on service delivery and guaranteed satisfaction. Customers' perceptions also indicate what they think about the problems associated with the particular service, its causes and possible solutions. It is important to note that Madina residents, as clients of GWCL, also have diverse perceptions about the inadequate water supply in their community. In other words, residents had varied reasons why they think water scarcity affects them, why it exists in the first place, and why it continues to exist without any hope in sight.

One major problem of many urban areas, especially in developing countries, is the rapid rate of urban growth. Accra, as the national capital, is not immune to this problem. Madina, as a peri-urban community, is one of the fast-growing areas in Accra. From the available literature, the area has an annual growth rate of about 8.3 per cent (as of 2000). This relatively high growth rate inevitably put much pressure on social services such as water supply in the area. It is the view of many residents that the water problem in Madina can partly be attributed to rapid growth in its population over the years. This was because enough had not been done in terms of facility expansion to meet the demands of an ever-growing population of the area. Besides, some residents also believed that the inability of GWCL to constantly change their equipment and increase the current density of pipelines largely accounted for their failure to meet the current demand of residents. The study found that those who live on higher grounds in Madina did not have water supply at all. The explanation offered was that these areas experience low pressure and the GWCL pumping machines could not pump enough to meet the demands of residents. Also, many homes in the study area were not connected to GWCL lines; thus, many homes did not have running taps.

Poverty has also been cited as one of the factors contributing to the water problem in Madina and the inability of residents to have adequate access to water. Since the poor were in the majority in the community, many of them cannot afford more extensive storage facilities. As a result, many cannot store enough for future use and have to buy water by the bucket each day. This compounds the problem and makes the majority even more vulnerable.

It is very instructive to point out that rapid democratisation has brought representation and liberties, but not rapid improvement in services to the people, especially the urban poor. Quite a good number of respondents believed that the age-long water problem in the area could be attributed to the fact that the central government did not care much about the people's welfare. In other words, their perception is that the central government does not care much about the people's water problem. As a result, no serious attempts have been made so far to bring the situation under control.

In a related development, some residents also thought that the water problem exists because most residents were poor and therefore cannot influence the central government to provide essential services such as water to the area. Also, some also argued that the area does not have a substantial number of "big men" and influential people who could influence the central government in terms of lobbying for the provision of water services. Thus, to them, they continue to suffer from water shortages because of the government's lukewarm attitude and their inability to influence government decisions. It is instructive also to note that the provision of social services such as education, electricity and water requires sizeable financial capital. However, this large financial outlay is most often than not beyond an individual's ability or a group of people. As a result, to drastically cut down on the cost of providing these capital intensive services, these services are better provided on large scales and a public basis. In other words, these services, such as water, are better equipped as a public good than as a private good. However, one major characteristic of urban societies, as noted by Louis Wirth in his work' Urbanism as a Way of Life', is a high degree of individualism. Here, communal living, which characterises rural settings, gives way to individualism, where people seek their self-interests and welfare. This individualistic tendency was clearly seen at play in the study area. As a result, instead of residents pulling their resources together into a shared pool to provide their water needs on a communal basis for all, each household instead seeks its interest. Thus, those who have the means could acquire larger and modern storage facilities that were used for storing water. In this vein, those residents who cannot afford such facilities due to financial limitations suffer unduly from the problem of water scarcity.

Therefore, it is pointed out that the water situation would have drastically reduced if residents had pulled their resources together and provided public water supply points to serve all instead of only individuals. In this case, offering social services such as water on an individual basis instead of on a communal basis is termed 'atomisation of service', which is a phenomenon of urban communities. Thus, the atomisation of social services such as water in Madina can thus be attributed to the individualistic nature of urban dwellers, which is a common feature of all urban societies

\subsection{Coping Strategies}

As a result of the water situation in Madina, residents have adopted some innovative ways to cope with the 
situation. The study found out that the coping strategies adopted depend on the economic factors such as employment type and income level in most cases.

\subsubsection{Storing Water}

In a water scarcity situation due to few lines and irregular flow, as is the case in Madina, storing water for everyday and future use becomes one way residents learn to cope with the situation. Personal observation and responses from residents attested that water storage is one strategy adopted in managing the acute water situation in the area. According to residents, one cannot survive in Madina without storing water. This helps them have water for regular use and helps cut the cost and time used on water. Different kinds of unimaginable containers ranging from small gallons, buckets, bowls, drums, and small tanks to large poly tanks, concrete overhead and underground tanks were used in storing water. It is important to note that the cost involved in acquiring some of these storage facilities is relatively high. Thus, it was only those with the financial means who were able to acquire these facilities and cope better. In the majority, the poor would have to depend on small gallons, bowls, buckets, and small drums for storing water for daily use.

4.3.2Rainwater Harvesting

Another essential mechanism adopted by residents to cope with the water situation was harvesting and making effective use of rainwater. Each time it was about to rain, residents' spectacle was a delight to watch. One sees all kinds of containers being carried by men, women and children looking for space to place them to harvest the coming rain. During one of the interactions with some women in Madina Old Road, they jokingly intimated that they even use their eating plates and chamber pots to collect rainwater for domestic use when it was about to rain. This clearly shows that harvesting rainwater is one crucial means adopted by residents in coping with the water problems in Madina. This also helped to cut down on the cost and time spent in searching for water. However, this is possible only in the rainy season.

4.3.3Use of Bagged (sachet) Water

In the absence of flowing taps, many residents depended on wells and water from vendors. These vendors supply their water with water tankers and often fetch from unknown sources. Many residents intimated that they could not ascertain the safety of the water they buy from these vendors since they did not know the sources from which they fetch their water. As a result, the water purchased from these private water vendors was only used for cooking and other domestic chores but not for direct drinking. Almost all respondents indicated that they totally depended on bagged (sachet) water or popularly known as 'pure water' for their drinking water. This put pressure on the family budget and increased the amount of money spent on the water.

4.3.4Using Public Toilets Instead of W.C.

As a result of the acute water shortage in Madina, many residents tend to prefer public toilet facilities. This was because household water closets (W.C) will increase the amount of water needed for household use, as each individual has to flush the toilet each time he/she visited the bathroom. Thus, more water would have to be made available for use. However, the use of public toilets goes a long way to cut down on each household's quantity of water. Those who continue to use their W.C.s usually use already used water or washed water to flush their W.C.s. Those who cannot do this had abandoned their W.C.s in the study area, although public toilets greatly inconvenience them.

4.3.5Taking a Bath Once in a Day

To drastically cut down on the quantity of water used, many households had to restrict bathing to only once a day. This was mostly done by men and children who take their baths most often than not, once in a day. Even those fortunate enough to bath twice a day often had to share a bucket of water with someone else. Thus, most people only bathe half a bucket of water at a time instead of a full bucket. During one of my routine visits to a house, the researcher witnessed a nursing mother with her baby bathe only a half bucket of water. The question is, how can a nursing mother and her child bathe half a bucket of water? This was the stark reality the residents of Madina had to grapple with. The effects of this sad and unfortunate situation are apparent. The personal hygiene of these people was significantly compromised. This can spread diseases and other skin infections among residents with its effects on their health conditions.

4.3.6 The Use of Greywater

Another critical coping strategy found among residents was the everyday use of greywater. In this case, the same quantity of soapy water used by different household members to wash is reused. Thus, after one person had finished washing his or her dresses, the soapy water used (greywater) is passed on to a second person also to clean his or her attire and the same water could be used to wash plates and other cooking utensils or even flush the W.C. The main reason behind this was to minimise the quantity of water used for washing and to also to cut down on the expenditure on water. Despite issues of hygiene, residents had no choice but to painfully adopt this strategy to better cope with the problem.

4.3.7Dependence on Hand-dug Wells

As a result of the inability of GWCL to supply enough water to meet the daily needs of residents, it has become vital to look for alternative sources of water supply as a way of coping with the situation. From the results of 
responses received from residents and personal observations by the researcher, it was found that quite a large number of residents also rely on hand-dug wells for their water needs. Table 2 below shows some identified coping strategies of residents.

Table 2: Coping strategies

\begin{tabular}{|l|l|}
\hline Coping Strategies & Description \\
\hline Water storage & Water stored in large containers on different sizes \\
\hline Rainwater harvesting & Water collected from roof during rainfalls \\
\hline Use of bagged (sachet) water & Packaged water in small-sized transparent plastic bags \\
\hline Purchasing water & Purchase of water from vendors \\
\hline Reduced consumption & Reduced water for bathing and laundry \\
\hline Multiple-use of water & Using the same water for different things \\
\hline
\end{tabular}

\subsection{Conclusions and Recommendations}

Perhaps more than any other sector, adequate water supply hits all the main social and economic development themes, such as poverty reduction and environmental sustainability. However, despite considerable investment in water supply in Ghana over the years, the number of people without access to basic water in urban and periurban areas continues to increase. It is important to note that uninterrupted access to treated and piped water is only significant in selected parts of urban areas such as Accra. Conversely, gaining access to clean and affordable water supply is a difficult daily struggle for many city dwellers, particularly for underserved areas.

The study revealed that GWCL had not produced enough water to meet the ever-increasing water demand of urban dwellers, including peri-urban communities such as Madina. A lack of financial resources has constrained the company to expand supply, high levels of unaccounted for water (about 50 per cent of water produced), growing population, and government subsidy reductions for water services. All these have contributed to the current "crisis" in the water delivery infrastructure, especially in urban areas such as Madina. Indeed, available statistics showed that access to clean water is available to about 60-70 per cent of urban dwellers. However, in urban areas, only 40 per cent of the population has water taps that flow. The study has shown that the age-long water crisis affects all aspects of its residents' social and economic lives. In this light, residents have developed coping strategies to be able to cope better with the situation. Also, households without access to piped water rely on a variety of less reliable and unhygienic sources such as mobile vendors (such as water tankers) and fixed vendors of GWCL water, wells, boreholes, streams, rainwater and commercial bottled or bagged water.

Quite clearly, a concerted strategy for managing water resources in urban areas needs to be put in place to minimise the effects of the current water problem staring most urban dwellers in Ghana's face, including those in Accra in general Madina in particular. Therefore, it is recommended that the Government of Ghana (GoG) continue to engage in open dialogue and consultation with a broad representation of all stakeholders regarding alternative approaches to expanding access to clean and affordable water, especially to urban dwellers where the problem is most severe. Because water, which also known as the "Blue Gold" is so essential to life, it must be made available to all to ensure that everyone has access to an efficient, responsive and sustainable water supply. This is because adequate water supply can reduce poverty to a minimum level and tremendously improve the living Standards of people, especially the urban poor. In a broader perspective, the current Millennium Development Goals (MDGs) and the Ghana Poverty Reduction Strategy (GPRS), which aim to reduce poverty by half by 2015, can only become a reality when water, the most basic of human needs, is made accessible to all.

It is recommended that urgent attention be focused on efficient household water use and alternative water sources for household consumption. Rainwater harvesting is relatively low, and efforts must be made to educate the general public on maximising rainwater harvesting and usage, particularly during the rainy season. Besides, there should be some public education on greywater usage in domestic settings to cut down on the cost of water consumption. The surest way to overcome this age-long problem is to look at multiple water sources as an effective coping mechanism with the situation. It is also recommended that the state invest more in water provision as a basic necessity, particularly in poor and underserved communities. In this case, the financial, logistic and human resource capacity of the Ghana Water Company must be enhanced to enable them to improve on the quality and delivery of their mandate. These would go a long way in addressing the problem in the future.

It is again recommended that for future research, there is the need to look into the extent to which rainwater harvesting could be promoted on a national scale to address the issue of water scarcity, particularly at the domestic level. So much rainwater go waste in Ghana, and it is about time we took a second look at how to maximise the use of this vital natural resource.

\section{References}

African Agenda (2004). Report on the International Conference on Water and Wastewater Management for Developing Countries. 28-30 July 2004, Victoria Falls (Zimbabwe). 
Aryeetey, E., \& Kanbur, R. (2006). Ghana's economy at half century: An overview of stability, growth and poverty.

Choe, K., Varley, R. C. G. \& Bijlani, H. U. (1996). Coping with intermittent water supply:Problems and prospects. Environmental Health Project. Dehra Dun, Uttar Pradesh, India: USAID.

Cudjoe F. (2004) Time Up for Commodification and Privatisation of Urban Water Supply in Ghana.

Dutta, V. \& Tiwari, A. P. 2005. Cost of services and willingness to pay for reliable urban water supply: A study from Delhi, India. Water Economics, Statistics and Finance, 5, 135-144.

Falkenmark, M and Rockstrom, J. (2004). Balancing Water for Human and Nature: The New Approach in Ecology, Earthscan Publication. London.

Fuchs, R. J., Brennan, E., Lo, F. C., Uitto, J. I., \& Chamie, J. (Eds.). (1994). Mega-city Growth and the Future. United Nations University Press.

Ghana. Statistical Service. (2002). 2000 Population and housing census: Summary report of final results. Ghana Statistical Service.

Green Dove Magazine (December, 2005). A publication of Green Earth Organization no. 36.

GSS (2000). Ghana Living Standards Survey: Report of the Fourth Round. Ghana Statistical services, Accra, Ghana.

Kudat, A., Alikram, A. \& Musayev, A. 1997. A social assessment of the Baku Water Supply Project. In: Cernea, M. M. \& Kudat, A. (eds.) Social assessments for better development: Case studies in Russia and Central Asia. Washington, DC: World Bank.

Kudat, A., Bell, M. E., Boland, J. J., Humplick, F., Madanat, S. \& Mukherjee, N. I. 1993. Reliability of urban water supply in developing countries: The emperor has no clothes. Working Paper. The World Bank.

Madanat, S., \& Humplick, F. (1993). A model of household choice of water supply systems in developing countries. Water Resources Research, 29(5), 1353-1358.

Molle, F., \& Mollinga, P. (2003). Water poverty indicators: conceptual problems and policy issues. Water policy, 5(5-6), 529-544.

Mycoo, M. (1996). Water provision improvements: A case study of Trinidad. Willingness to pay, pricing policy, cost reduction and institutional strengthening. PhD Thesis, McGill University.

Neubeck, K.J., \& Neubeck, M.A. (1997). Social problems - a critical approach (4th ed.). McGraw-Hill.

Oppong, C. (2004) Women's Roles and Demographic Changes in Sub-Saharan Africa

Paoletto, T. I. E. N. G. (1999). Cities and the environment: new approaches for eco-societies. United Nations Univ.

PRONET (2002). Draft Report on Review of Water and Sanitation Services in Ghana.

Ricardo, P. (2001). The Water Manifesto: Arguments for a World Water Contract, Dhaka Bangladeswh, University Press Limited.

Rockstrom, J. (2001). Green Water Security for the Food Makers of Tomorrow: Windows for Opportunity in Drought- Prone Savannahs, Water Science and Technology,43 (4), pp. 71-78

Vlachos, E., \& James, L.D. (1993). Drought Impacts. In: V. Yevjevich, L. V. Cunha, E. Vlachos (Eds.) Coping with Droughts. Water Resources Publications, Littleton, CO, pp. 44-73.

WaterAid (2005). Urban Sector assessment Report. www.wateraid.org

WHO/UNICEF (2005). Joint Monitoring Programme for Water Supply and Sanitation:Water for Life- Making it Happen. WHO/UNICEF publications, Geneva, Switzerland.

Winpenny J. (1994). Managing water as an economic resource. Routledge.

Zane, L. Miller (1973). The Urbanization of Modern America- A Brief History. Harcourt Brace Jovanovich, Inc., Cincinnati, USA.

ZÉRAH, M.-H. (1998). How to assess the quality dimension of urban infrastructure: The case of water supply in Delhi. Cities, 15, 285-290.

ZÉRAH, M.-H. (2000b). Household strategies for coping with unreliable water supplies: The case of Delhi. Habitat International, 24, 295-307. 